\title{
KESTABILAN MODEL BIOEKONOMI SISTEM MANGSA PEMANGSA SUMBER DAYA PERIKANAN DENGAN PEMANENAN PADA POPULASI PEMANGSA
}

\author{
Rustam \\ Jurusan Matematika Universitas Sembilanbelas November Kolaka \\ Email: rustam.math06@gmail.com/rustam.math@usn.ac.id \\ Mobile Phone: +6285342204224
}

\begin{abstract}
Abstrak
Sumber daya perikanan dengan karakteristik akses terbuka memungkinkan terjadinya eksploitasi berlebihan, sehingga konsep bioekonomi perikanan dikembangkan dengan harapan mencegah terjadinya eksploitasi berlebihan pada sumber daya perikanan. Penelitian ini bertujuan untuk menentukan kestabilan titik keseimbangan model bioekonomi sistem mangsa pemangsa sumber daya perikanan dengan pemanenan pada populasi pemangsa. Model bioekonomi sistem mangsa pemangsa sumber daya perikanan yang dibahas berdasarkan pada asumsi awal yaitu pemanenan hanya pada populasi pemangsa. Kestabilan titik keseimbangan ditentukan dengan metode linearisasi sistem. Hasil linearisasi mengarahkan pada diperolehnya persamaan krakteristik dan nilai eigen yang merupakan acuan penentuan sifat kestabilan titik keseimbangan. Kestabilan titik keseimbangan juga ditentukan dengan menggunakan uji kestablan Hurwitz. Dari hasil penelitian diperoleh tiga titik keseimbangan yang salah satunya merupakan titik keseimbangan interior. Analisis kestabilan menggunakan metode pelinearan dan uji kestabilan Hurwitz menunjukkan bahwa titik keseimbangan interior yang diperoleh merupakan titik keseimbangan yang stabil asimptotik. Hal ini bermakna bahwa populasi mangsa dan pemangsa akan tetap lestari meskipun dilakukan pemanenan pada populasi pemangsa.
\end{abstract}

Kata Kunci: Model Bioekonomi, Titik Keseimbangan, Kestabilan, Stabil Asimptotik, Titik Interior

\section{Pendahuluan}

Sumber daya alam (SDA) adalah segala sesuatu yang muncul secara alami yang dapat digunakan untuk pemenuhan kebutuhan manusia. Pada umumnya, SDA berdasarkan sifatnya dapat digolongkan menjadi SDA yang dapat diperbaharui dan SDA yang tak dapat diperbaharui. SDA yang dapat diperbaharui merupakan kekayaan alam yang dapat terus ada selama penggunaannya tidak dieksploitasi secara berlebihan. Tumbuhan dan hewan adalah contoh SDA yang dapat diperbahrui yang mana jumlahnya sangatlah berlimpah secara umum di negara Indonesia. Walaupun jumlahnya berlimpah penggunaannya harus tetap dibatasi dan dijaga agar terus berkelanjutan dan terjaga kelestariannya sehingga manajemen sumber daya alam terbarukan merupakan suatu hal yang penting.

Sumber daya perikanan merupakan sumber daya alam terbarukan yang mempunyai karakteristik yang unik yaitu merupakan sumber daya milik umum (common property). Akibatnya pemanfaatan sumber daya perikanan bersifat open acces artinya semua orang dapat melakukan kegiatan penangkapan ikan di suatu wilayah perairan tanpa adanya pembatasan. Karakteristiknya tersebut dalam pemanfaatannya dapat mengalami overfishing atau eksploitasi berlebihan yaitu tingkat penangkapan ikan meningkat hingga mengganggu keseimbangan populasi ikan yang berakibat tidak lagi diperoleh keuntungan dari sumber daya perikanan tersebut bahkan dapat mengakibatkan kepunahan populasi ikan. Sehingga dibutuhkan manajemen perikanan dengan tujuan menjamin konservasi sumber daya perikanan di masa mendatang tetap lestari dan tetap memberikan keuntungan ekonomis pada masyarakat secara regular dengan menerapkan manajemen yang tepat. Pada konsep biologi, interaksi biologi yang biasa dijumpai dalam ekosistem adalah interaksi mangsa pemangsa. Salah satu contoh interaksi mangsa pemangsa dalam perikanan adalah interaksi antara bibit ikan bandeng (nener) dan ikan kakap putih (lates calcarifer). Bentuk interaksinya yaitu ikan kakap putih merupakan pemangsa bagi bibit ikan bandeng (nener), dimana ikan kakap putih merupakan pemangsa yang rakus dan aktif memburu mangsanya (Fahmi, 2000).

Beberapa penelitian terdahulu yang mendasari penelitian ini, antara lain penelitian Chakraborty dkk., (2011) yaitu model bioekonomi sistem mangsa pemangsa sumber daya perikanan dengan waktu tunda, dimana terdapat dua zona populasi mangsa. Selain itu, Chakraborty dkk., (2011) 
pada tahun yang sama juga meneliti tentang kontrol optimal model mangsa pemangsa sumber daya perikanan dengan tahapan struktur dimana permasalahan yang dikaji terdiri dari 2 bagian. Bagian pertama dilakukan penambahan faktor pemanenan pada populasi mangsa dan pada bagian kedua penambahan faktor pemanenan dilakukan pada populasi pemangsa. Sedangkan Prastiwi (2013) mengkombinasikan kedua jenis penelitian Chakraborty dkk. tersebut untuk melihat pengaruh waktu tunda pada pertumbuhan pemangsa dengan pemanenan dikenakan pada populasi mangsa zona bebas penangkapan ikan. Tujuan penelitian ini adalah menentukan titik keseimbangan dan uji kestabilan titik keseimbangan sistem mangsa pemangsa sumber daya perikanan dengan pemanenan pada populasi pemangsa.

\section{Metodologi}

Penelitian ini merupakan penelitian yang bersifat studi literatur. Metodologi yang digunakan adalah membangun model bioekonomi sistem mangsa pemangsa sumber daya perikanan dengan asumsi pemanenan dilakukan pada populasi pemangsa. Model yang telah terbentuk ditentukan titik keseimbangannya kemudian dilakukan uji sifat kestabilan titik keseimbangan menggunakan metode linearisasi dan uji kestabilan Hurwitz. Untuk mengetahui kepastian kebenaran solusi eksak yang telah diperoleh dilakukan simulasi numerik. Software komputasi yang digunakan pada simulasi numerik adalah Maple dan Matlab.

\section{Hasil dan Pembahasan}

\subsection{Hasil}

Model bioekonomi sumber daya perikanan dengan pemanenan dilakukan pada populasi pemangsa adalah sebagai berikut

$$
\begin{aligned}
& \frac{d x}{d t}=r x\left(1-\frac{x}{K}\right)-\sigma_{1} x+\sigma_{2} y-\frac{\alpha x z}{a+x} \\
& \frac{d y}{d t}=s y\left(1-\frac{y}{L}\right)+\sigma_{1} x-\sigma_{2} y \\
& \frac{d z}{d t}=\frac{\beta \alpha x z}{a+x}-k z-\gamma z^{2}-q E z \\
& (p q z-c) E-m=0 .
\end{aligned}
$$

Dari model bioekonomi sumber daya perikanan pada persamaan (1) diperoleh tiga titik keseimbangan yaitu $T_{1}=\left(0,0,0,-\frac{m}{c}\right), T_{2}=\left(\tilde{x}, \tilde{y}, 0,-\frac{m}{c}\right)$, dan $T_{3}=\left(x *, y^{*}, z^{*}, E^{*}\right)$ dimana $x^{*}=\frac{L \sigma_{2} y^{*}-L s y^{*}+s y^{* 2}}{L \sigma_{1}}, y *=\frac{1}{\sigma_{2}}\left(\frac{r}{K} x *^{2}-r x *+\sigma_{1} x *+\frac{\alpha x * z *}{a+x *}\right), z^{*}=\frac{1}{\gamma}\left(\frac{\beta \alpha x^{*}}{a+x^{*}}-k-q E^{*}\right), E^{*}=\frac{m}{p q z^{*}-c}$.

Titik keseimbangan $T_{3}=\left(x *, y *, z^{*}, E^{*}\right)$ merupakan titik keseimbangan interior yaitu $x *>0, y *>0, z *>0$, dan $E^{*}>0$ dengan syarat

$$
\sigma_{2} y^{*}-s y *\left(1-\frac{y^{*}}{L}\right)>0, \frac{r}{K} x *^{2}-r x *+\sigma_{1} x *+\frac{\alpha x * z^{*}}{a+x *}>0, \frac{\beta \alpha x^{*}}{a+x^{*}}-k-q E^{*}>0, p q z^{*}-c>0 .
$$

Titik keseimbangan $T_{1}$ dan $T_{2}$ tidak dilakukan analisis kestabilan karena titik keseimbangan ini bukan merupakan titik keseimbangan interior. Analisis kestabilan hanya dilakukan pada titik keseimbangan interior yang merupakan syarat kewujudan populasi.

Jika persamaan (1) dituliskan dalam bentuk

$$
f=r x\left(1-\frac{x}{K}\right)-\sigma_{1} x+\sigma_{2} y-\frac{\alpha x z}{a+x}, g=s y\left(1-\frac{y}{L}\right)+\sigma_{1} x-\sigma_{2} y, h=\frac{\beta \alpha x z}{a+x}-k z-\gamma z^{2}-q E z,
$$

maka diperoleh matriks Jacobi dari persamaan (2) sebagai berikut 


$$
A=\left(\begin{array}{lll}
\frac{\partial f}{\partial x} & \frac{\partial f}{\partial y} & \frac{\partial f}{\partial z} \\
\frac{\partial g}{\partial x} & \frac{\partial g}{\partial y} & \frac{\partial g}{\partial z} \\
\frac{\partial h}{\partial x} & \frac{\partial h}{\partial y} & \frac{\partial h}{\partial z}
\end{array}\right) .
$$

dengan mensubstitusi titik keseimbangan $T_{3}=\left(x^{*}, y^{*}, z^{*}, E^{*}\right)$ pada matriks Jacobi $A$, diperoleh

$$
A^{*}=\left(\begin{array}{ccc}
r-\frac{2 r x *}{K}-\sigma_{1}-\frac{\alpha z *}{a+x *}+\frac{\alpha x * z *}{(a+x *)^{2}} & \sigma_{2} & -\frac{\alpha x *}{a+x *} \\
\sigma_{1} & s-\frac{2 s y *}{L}-\sigma_{2} & 0 \\
\frac{\beta \alpha z *}{a+x *}-\frac{\beta \alpha x * z *}{(a+x *)^{2}} & 0 & \frac{\beta \alpha x *}{a+x *}-k-2 \gamma z *-q E^{*}
\end{array}\right) .
$$

Persamaan karakteristik dari matriks Jacobi $A^{*}$ adalah $\left|A^{*}-\lambda I\right|=0$. Dengan menyelesaikan persamaan karakteristik $\left|A^{*}-\lambda I\right|=0$ diperoleh bentuk

$$
\lambda^{3}+p_{2} \lambda^{2}+p_{1} \lambda+p_{0}=0,
$$

dimana

$$
\begin{aligned}
p_{0}= & -\left(r-\frac{2 r x *}{K}-\sigma_{1}-\frac{\alpha z *}{a+x *}+\frac{\alpha x * z *}{(a+x *)^{2}}\right)\left(s-\frac{2 s y *}{L}-\sigma_{2}\right)\left(\frac{\beta \alpha x *}{a+x *}-d-2 \gamma z *-q E^{*}\right) \\
& -\left(\frac{\beta \alpha z *}{a+x *}-\frac{\beta \alpha x * z *}{(a+x *)^{2}}\right)\left(s-\frac{2 s y *}{L}-\sigma_{2}\right)\left(\frac{\alpha x *}{a+x *}\right) \\
& +\left(\frac{\beta \alpha x *}{a+x *}-d-2 \gamma z *-q E^{*}\right) \sigma_{1} \sigma_{2}, \\
p_{1}= & \left(r-\frac{2 r x *}{K}-\sigma_{1}-\frac{\alpha z *}{a+x *}+\frac{\alpha x * z *}{(a+x *)^{2}}\right)\left(s-\frac{2 s y *}{L}-\sigma_{2}\right) \\
& +\left(r-\frac{2 r x *}{K}-\sigma_{1}-\frac{\alpha z *}{a+x *}+\frac{\alpha x * z *}{(a+x *)^{2}}\right)\left(\frac{\beta \alpha x *}{a+x *}-d-2 \gamma z *-q E^{*}\right) \\
& +\left(s-\frac{2 s y *}{L}-\sigma_{2}\right)\left(\frac{\beta \alpha x *}{a+x *}-d-2 \gamma z *-q E^{*}\right)+\left(\frac{\beta \alpha z *}{a+x *}-\frac{\beta \alpha x * z *}{(a+x *)^{2}}\right)\left(\frac{\alpha x *}{a+x *}\right)-\sigma_{1} \sigma, \text { dan } \\
p_{2}= & -\left(\left(r-\frac{2 r x *}{K}-\sigma_{1}-\frac{\alpha z *}{a+x *}+\frac{\alpha x * z *}{(a+x *)^{2}}\right)+\left(s-\frac{2 s y *}{L}-\sigma_{2}\right)+\left(\frac{\beta \alpha x *}{a+x *}-d-2 \gamma z *-q E^{*}\right)\right) .
\end{aligned}
$$

Menurut uji kestabilan Hurwitz, titik keseimbangan $T_{3}=\left(x^{*}, y^{*}, z^{*}, E^{*}\right)$ stabil asimptotik apabila $p_{0}, p_{1}, p_{2}>0$ dan $p_{2} p_{1}-p_{0}>0 . \mathrm{Uji}$ kestabilan Hurwitz merupakan suatu metode yang dipertimbangkan untuk menguji kestabilan titik keseimbangan dari sistem dinamik linear dengan koefisien konstan. Matriks Hurwitz diberikan sebagai berikut

$$
\begin{aligned}
& H_{1}=\left(p_{n-1}\right), \\
& H_{2}=\left(\begin{array}{cc}
p_{n-1} & p_{n-3} \\
1 & p_{n-2}
\end{array}\right), \\
& H_{3}=\left(\begin{array}{ccc}
p_{n-1} & p_{n-3} & p_{n-5} \\
1 & p_{n-2} & p_{n-4} \\
0 & p_{n-1} & p_{n-3}
\end{array}\right),
\end{aligned}
$$


sampai matriks $H_{n}$. Disini, nilai $p_{j}$ didefinisikan bernilai 0 jika $j$ bernilai negatif. Uji kestabilan Hurwitz (Willems, 1970 dan Jeffries, 1989). Diberikan sistem dinamik

$$
\frac{d x}{d t}=A x \text {. }
$$

Misalkan sistem pada persamaan (3) mempunyai trajektori konstan 0. Setiap matriks Hurwitz mempunyai determinan dengan nilai positif jika dan hanya jika setiap bagian riil dari nilai eigen matriks $A$ bernilai negatif dan 0 merupakan suatu trajektori atraktor, yaitu titik keseimbangan 0 stabil asimptotik.

Untuk nilai $n$ yang kecil, uji stabilan Hurwitz menyatakan bahwa masing-masing matriks Hurwitz mempunyai determinan dengan nilai positif jika dan hanya jika, untuk

$$
\begin{array}{ll}
n=1, & p_{0}>0 \\
\mathrm{n}=2, & \mathrm{p}_{0}, p_{1}>0 \\
n=3, & \mathrm{p}_{0}, p_{1}, p_{2}>0, \quad p_{2} p_{1}-p_{0}>0 \\
n=4, & \mathrm{p}_{0}, p_{1}, p_{2}, p_{3}>0, \quad p_{3}, p_{2}, p_{1}-p_{1}{ }^{2}-p_{0} p_{3}{ }^{2}>0 .
\end{array}
$$

Dengan demikian kestabilan titik keseimbangan 0 dapat diketahui dengan memperhatikan nilai-nilai koefisien dari persamaan karakteristik matriks $A$ (Toaha, 2013).

Hasil analisis kestabilan menggunkan metode linearisasi dan uji kestabilan Hurwitz menunjukkan bahwa titik keseimbangan $T_{3}$ merupakan titik keseimbangan yang stabil asimptotik. Nilai parameter yang digunakan mengacu pada nilai parameter pada tabel 1 (lampiran). Dengan mempertimbangkan beberapa penelitian lain yang relevan dengan penelitian ini, juga digunakan parameter $K=1.000, L=1.000, p=5, c=5$, dan $v=0,5$. Gambar 1 (lampiran) menunjukkan jumlah populasi $x$ (mangsa pada zona bebas), $y$ (mangsa pada zona reservasi), dan $z$ (pemangsa) dalam kurun waktu 10 tahun.

Model bioekonomi sumber daya perikanan seperti pada persamaan (1), dengan menggunakan nilai parameter pada Tabel 1 dan nilai parameter penelitian lain yang relevan dengan penelitian ini diperoleh titik keseimbangan interior

$$
x^{*}=898,7165797, y^{*}=965,4427230, z^{*}=373,1056922, E^{*}=0,02694650125 .
$$

Dengan menggunakan metode linearisasi diperoleh nilai-nilai eigen dari persamaan karakteristik yaitu $\lambda_{1}=-1,7504487196, \lambda_{2}=-0,65468484132$, dan $\lambda_{3}=-0,36173736420$.

Nilai-nilai eigen yang diperoleh terlihat bahwa semuanya bernilai negatif. Berdasarkan hal ini, disimpulkan bahwa titik keseimbangan $T_{3}=\left(x^{*}, y^{*}, z^{*}, E^{*}\right)$ stabil. Titik keseimbangan $T_{3}=\left(x *, y^{*}, z^{*}, E^{*}\right)$ juga dianalisis kestabilannya menggunakan uji kestabilan Hurwitz, dimana diperoleh nilai $p_{0}=0,4300979809, p_{1}=2,048628021, p_{2}=2,780416788$, dan $\quad p_{2} p_{1}-p_{0}=$ 5,265941761. Karena $p_{0}>0, p_{1}>0, p_{2}>0$, dan $p_{2} p_{1}-p_{0}>0$, maka menurut uji kestabilan Hurwitz, titik keseimbangan $T_{3}=\left(x *, y *, z^{*}, E^{*}\right)$ merupakan titik keseimbangan yang bersifat stabil asimptotik. Hal ini bermakna bahwa jika diambil nilai awal tertentu (misalkan 500) untuk masingmasing populasi, maka dalam waktu yang lama jumlah populasi mangsa zona bebas menuju ke 898,7165797, populasi mangsa zona reservasi menuju ke 965,4427230, populasi pemangsa menuju ke 373,1056922, dan tingkat usaha pemanenan akan menuju ke 0,02694650125. Secara umum dapat dikatakan bahwa jumlah populasi mangsa zona bebas, mangsa zona reservasi, dan pemangsa akan tetap eksis dalam jangka waktu yang lama dan tidak akan terjadi kepunahan.

\subsection{Pembahasan}

Hasil penelitian menunjukkan bahwa perilaku sistem dengan pemanenan pada populasi pemangsa $(z)$ memberikan pengaruh pada populasi yang dipanen yaitu jumlah populasi pemangsa mengalami penurunan jumlah yang cukup signifikan dari nilai awal yang diberikan. Berbeda halnya dengan populasi mangsa pada zona bebas $(x)$ dan populasi mangsa pada zona reservasi ( $y$ ) yang mengalami pertumbuhan yang cukup signifikan. Hal ini disebabkan karena populasi mangsa zona bebas dan populasi mangsa pada zona reservasi tidak dilakukan pemanen. Hasil penelitian model 
bioekonomi sistem mangsa pemangsa dengan pemanenan pada populasi pemangsa memberikan hasil yaitu diperoleh tiga titik keseimbangan yang salah satunya merupakan titik keseimbangan interior dan mempunyai sifat kestabilan stabil asimptotik. Sehingga hal ini memberikan pengertian bahwa jumlah populasi mangsa dan pemangsa akan tetap lestari meskipun dilakukan pemanenan pada populasi pemangsa yang tentunya dari sisi ekonomi dengan pemanenan populasi pemangsa tersebut akan memberikan keuntungan ekonomis.

\section{Kesimpulan}

Salah satu titik keseimbangan yang diperoleh dari model bioekonomi sistem mangsa pemangsa sumber daya perikanan dengan pemanenan pada populasi pemangsa merupakan titik keseimbangan interior yang mempunyai sifat kestabilan stabil asimptotik. Sehingga dapat ditarik kesimpulan bahwa bahwa jumlah populasi mangsa zona bebas, zona reservasi, dan pemangsa akan tetap lestari dalam waktu yang cukup lama dan dijamin tidak akan terjadi kepunahan meskipun dilakukan pemanenan pada populasi pemangsa yang tentunya dari sisi ekonomi dengan pemanenan populasi pemangsa tersebut akan memberikan keuntungan ekonomis. Sebagai upaya tindak lanjut dari penelitian ini, penulis memberi saran dilakukan variasi model dimana pemanenan tidak hanya dilakukan pada populasi pemangsa, namun juga dilakukan pemanenan pada populasi mangsa zona bebas dan populasi mangsa zona reservasi.

\section{Daftar Pustaka}

Chakraborty, K., Chakraborty, M., dan Kar, T.K. (2011). Bifurcation and Control of a Bioeconomic Model of a Prey-Predator System with a Time Delay. Nonlinear Analysis: Hybrid Systems. 5: 613-625.

Chakraborty, K., Chakraborty, M., dan Kar, T.K. (2011). Optimal Control of Harvest and Bifurcation of Prey-Predator Model with Stage Structure. Applied Mathematics And Computation. 217: 8778-8792.

Fahmi. (2000). Jenis Ikan Pemangsa di Tambak Tradisional dan Cara Penanganannya. Jurnal Oseana. 25(1): 21-30.

Haberman, R. (1977). Mathematical Models An Introduction to Applied Mathematics. Prentice-Hall, Inc., New Jersey.

Jeffries, C. (1989). Mathematical Modeling in Ecology. Birakhaauser, Boston.

Liu, C., Zhang, Q., dan Huang, J. (2011). The Dynamics and Control of a Harvested DifferentialAlgebraic Prey-Predator Model. International Journal of Information and Systems Sciences. 7(1): 103-113.

Prastiwi, L. (2013). Kontrol Optimal Model Bioekonomi Mangsa-Pemangsa dengan Waktu Tunda. Tesis tidak diterbitkan. Surabaya: Program Pascasarjana ITS.

Subiono. (2012). Sistem Linier dan Kontrol Optimal. Jurusan Matematika FMIPA-ITS, Surabaya.

Toaha, S. (2013). Pemodelan Matematika dalam Dinamika Populasi. Dua Satu Press, Makassar.

Willems, J.L. (1970). Stability Theory of Dynamical Systems. Thomas Nelson \& Sons, London. 